\title{
Longitudinal Continuity
}

\author{
Christine D. Ford, EdD ${ }^{7}$, Premal G. Patel, MD², Victor S. Sierpina, MD², \\ Mark W. Wolffarth, $M D^{2}$, and Judith L. Rowen, $M D^{3}$
}

'University of Texas Health Science Center at Houston, Houston, TX, USA; ${ }^{2}$ University of Texas Medical Branch, Galveston, TX, USA; ${ }^{3}$ Carle Illinois College of Medicine, Champaign, IL, USA.

J Gen Intern Med 34(11):2304

DOI: $10.1007 / \mathrm{s} 11606-019-05274-2$

(C) Society of General Internal Medicine 2019

$\mathrm{W}$ e are pleased at the interest in SCOPE from students and our international colleagues and welcome the opportunity to extend the conversation about student interest in primary care careers. Geier, Frese, and Deutch's description of LeiKA's social component is very similar to what we have done in the SCOPE program. All of our students and faculty were invited to a potluck every spring and fall at a faculty member's house to foster connections with one another. Our workshops also served a social function; breakfast or dinner was served, depending on the time of day, and the workshop structure encouraged discussion and interaction. Ford's dissertation research (unpublished) has confirmed that the social aspects of SCOPE, both formal and informal, influenced student career choice, particularly in encouraging primary care career persistence in students.

To address to Nathan's questions regarding some of SCOPE's outcomes and possible barriers to participation, we offer the following responses:

- We found it challenging to assess changes to institutional perceptions of primary care. Anecdotally we heard from clerkship directors and other teaching faculty that SCOPE students were more responsible and more engaged than the typical student and proved to be excellent ambassadors not only for SCOPE but also for primary care. Perhaps more telling was the increased faculty interest in adding SCOPE clinic spots for students in specialty areas such as Oncology and Psychiatry. While SCOPE was originally conceived solely as a primary care-focused project, we found that many of the principles we emphasized had applicability across a variety of disciplines. Additionally, Ford's dissertation research (unpublished) found that students who participated in SCOPE but did not ultimately choose a primary care career described a greater appreciation for the contributions primary care physicians make to the health care system and an increased commitment to partner effectively with their primary care colleagues. Our hope is that SCOPE's participants continue to be agents of change regarding primary care attitudes in their residencies and future practices.

Published online August 13, 2019
- Regarding factors that influenced students' choice not to participate in SCOPE during third year, we found that scheduling concerns were a frequently cited reason. To participate in SCOPE during third year, students were limited in the number of away rotations they could take, and some students worried they would not gain the diversity of experiences they desired without those away rotations. Another barrier to continued participation was the inability to keep working with the same preceptor. Students formed relationships with their preceptors and were sometimes reluctant to switch to a new person if their preceptor left the university or their schedule became incompatible with SCOPE.

- Our application process was less focused on selecting students who expressed a strong interest in primary care than in selecting students who were patient-centered and recognized the role physicians play in addressing health disparities. The scenarios in the multiple mini interviews were designed to gauge the students' communication and teamwork skills, traits that are important in any physician. Given the relatively small number of students SCOPE could take each year, our goal was to admit students who showed promise as patient-centered, compassionate physicians and help them grow. It is difficult to know if keeping a random application process would have attracted more undecided or specialty-leaning students. Bennett and Phillips, ${ }^{1}$ conceptual model of student career choice suggests that undecided and primary care positive but not committed students hold the greatest promise for increasing the primary care workforce.

Corresponding Author: Christine D. Ford, EdD; University of Texas Health Science Center at Houston, Houston, TX, USA (e-mail: Christine.D.Ford@uth.tmc.edu).

\section{REFERENCE}

1. Bennett KL, Phillips JP. Finding, recruiting, and sustaining the future primary care physician workforce: a new theoretical model of specialty choice process. Acad Med. 2010 Oct 1;85(10):S81-8.

Publisher's Note Springer Nature remains neutral with regard to jurisdictional claims in published maps and institutional affiliations. 